\title{
A Systematic Review on the Clinical Outcomes of Dipeptidyl Peptidase-4 Inhibitors in Type 2 Diabetes Mellitus Patients
}

\author{
Prudence A. Rodrigues*, Ndayishimye Samuel \\ Department of Pharmacy Practice, PSG College of Pharmacy, Peelamedu, Coimbatore 641004, Tamil Nadu, INDIA.
}

\begin{abstract}
Context: clinical outcomes of Dipeptidyl Peptidase-4 inhibitors can be beneficial for the patients in controlling high blood sugar it can also cause potential adverse effects Aim: The main objective of this study was to assess the risks and benefits of Dipeptidyl peptidase-4inhibitors (DPP-4I) in type 2 diabetes mellitus patients. Method: systematical articles on Dipeptidyl peptidase-4 inhibitors were reviewed from the year 2015 up to 2017 from 3 databases such as: EMBASE, COCHRANE and MEDSCAPE and some diabetes associations, the main such were: DPP-4 inhibitor, incretin, type 2 diabetes mellitus, Vildagliptin, Sitagliptin, Linagliptin, Saxagliptin, Alogliptin, 69 citations were included after screening for duplication and biased articles. Results: All DPP-4I are efficacious for improving blood glucose level among type 2 diabetes mellitus patients without causing hypoglycemic effects, and they can be used as monotherapy or in combination with other antidiabetic agents, Linagliptin offer uniqueness properties due to its non-renal excretion it improves microalbuminuria, whereas remaining DDP-4I cause a marginal changes on renal function, there is no hepatotoxicity among the DPP-4I no dose adjustment for Linagliptin, Sitagliptin, saxagliptin due non-hepatic excretion, only dose reduction is required for patients with minor hepatic functional impairment taking Vildagliptin and saxagliptin due to their partially elimination via liver,DPP-4I also protect patients for cardiovascular complications due its ability of reducing or maintaining the stability of body weight and lipid profile. They also show a low risk for increasing pancreatitis among T2DM and the others side effect were comparable less when compared to other anti-hyperglycemic agents. Conclusion: DPP-4I significantly control blood sugar level by decreasing glycated hemoglobin, fasting blood sugar, random blood sugar and they are not associated with hypoglycemic events they also minimize cardiovascular complications by reducing fats and weight in type 2 diabetes mellitus patients, in addition DPP-4I helps in renal and liver protection. Over all, DPP-4I reduce morbidity and mortality rate among T2DM patients.
\end{abstract}

Key words: DPP-4I, T2DM, Incretin, Saxagliptin, Linagliptin, Sitagliptin, Vildagliptin, Alogliptin.

\section{INTRODUCTION}

Diabetes mellitus is a metabolic disorder occurs when the body does not produce enough insulin or body does not respond to the produced insulin. ${ }^{1}$ Early symptoms of DM are frequent urination, increased thirst, hunger, excessive fatigue, loss or gain of weight and slow healing of wound..$^{2-4}$ Chronic hyperglycemia is associated with end organ damage, dysfunction, and failure in organs and tissues including the retina, kidney, nerves, heart, and blood vessels. ${ }^{5} \mathrm{~A}$ large number of diabetic patient die from cardiovascular complications such as: stroke, ischemic heart diseases, ${ }^{6-10}$ in the last three decades the incidence of diabetes mellitus has boosted from 30 million in 1985 to 425 million in 2018, and it is set to reach 629 million by 2045 When it is not appropriately managed. ${ }^{11-13}$ In India, DM is the second highest prevalent disease approximately 1 into 10 in Indian population has $\mathrm{DM}^{14-18}$ the desired general goals of the treatment of diabetes are to avoid acute metabolic decompensation, prevent or delay the appearance of late disease complications, decrease mortality, and maintain a good quality of life. As for chronic complications of the disease, it is clear that good control of glycemia makes it possible to reduce the incidence of microvascular complications
DOI: 10.5530/ijopp.11.3.31

Address for correspondence: Dr. Prudence A. Rodrigues, Department of Pharmacy Practice, PSG College of Pharmacy, Peelamedu, Coimbatore 641004, Tamil Nadu, INDIA. Phone no: 919952582356 Email Id: ndayisamukvm@gmail. com

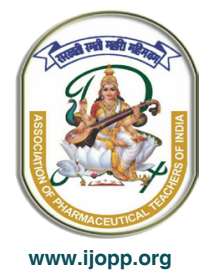


(retinopathy, nephropathy, and neuropathy) ${ }^{19}$ these can be achieved by keeping blood sugar near to a normal range ${ }^{20}$ avoiding hypoglycemia effects ${ }^{21}$ and minimizing risk factors such obesity and encouraging physical exercises. $^{22}$ The relatively long half-lives of sitagliptin, Linagliptin and Alogliptin facilitate once-daily dosing (Table 1). Saxagliptin is also suitable for once-daily dosing as a result of the presence of the active metabolite, BMS-510849, which inhibits DPP-423. The shorter half-life of vildagliptin requires twice-daily dosing. ${ }^{23}$ As vildagliptin and saxagliptin are partially eliminated via the liver, dose reductions are also recommended in patients with hepatic functional impairment. ${ }^{23-24}$ The DPP-4 inhibitor act by increasing insulin production, decreasing glycogen production, slow gastric emptying and causing patient to feel satisfaction ${ }^{21}$ these oral antidiabetic agents are more efficacious to control glycated hemoglobin, fasting blood sugar, postprandial blood sugar, blood pressure, fat metabolism and it is very safe for the hypoglycemia effect, ${ }^{25}$ Linagliptin offer an extra benefit of nephroprotection due to its biliary excretion. ${ }^{26}$ The only drawback of DPP-4 inhibitors have been linked with an increased risk of pancreatitis ${ }^{27-28}$ and minor adverse events like GIT problems. ${ }^{29-30}$

\section{METHODOLOGY}

Systematically articles were reviewed Dipeptidyl peptidase-4inhibitors 2015-2017. Main search concepts were DPP-4I, incretin, vildagliptin, sitagliptin, linagliptin, saxagliptin, Alogliptin, types 2 diabetes mellitus. Databases such as COCHRANE, EMBASE, and MEDSCAPE were searched and literatures were collected and screened to avoid bias and duplicate for this study. Data also are collected from various associations such as Diabetes and endocrine associations, medical association and their associated sites. In this study 69 citations were reviewed.

\section{RESULTS}

Clinical outcomes of dipeptidyl peptidase-4inhibitors are summarized according several studies on various parameters. Sitagliptin was the first selective inhibitor of DPP-4, followed by vildagliptin, saxagliptin, Alogliptin and most recently Linagliptin. ${ }^{28}$ (Table 1)

\section{Glycemic Control}

DPP-4I show a significant improvement for $\mathrm{HbA} 1 \mathrm{c}$ for a weighted mean difference of $<0.8 \%$ as monotherapy ${ }^{26,31}$ Naoto et al. in a 24 week follow up in a comparative study between Linagliptin and Sitagliptin involving 42 patients both male and female ${ }^{26}$ author concluded that both drugs significantly improve HBA1c, fasting blood sugar and postprandial blood sugar, ${ }^{32-33}$ Paul Craddy et al. In a meta-analysis comparison study of DPP-4I involving 83 RCTs concluded that there are no major differences between them with regard to improvements in glycemia control. ${ }^{34}$ Another study involving a total of 36 double-blind RCTs by M.B. Rehman et al. allowing analyses of 54,664 patients author concluded that DPP4I improve blood sugar and are not associated with risk of hypoglycemic effect in patients with types 2 diabetes mellitus. ${ }^{35-37}$ among five DPP-4 inhibitors such as Alogliptin, linagliptin, saxagliptin, sitagliptin, and vildagliptin showed almost similar efficacy in controlling blood glucose in the treatment of type 2 diabetes mellitus, either as monotherapy or in combination therapy.

\section{Renal Function}

Drug excretion through kidney may cause declining of renal function due to overexposure, in normal ways the renal function starts to decline with the age, in case of diabetes mellitus patients; diabetic nephropathy which is one of diabetic complications rises and cause mortality and morbidity among them. ${ }^{38}$ The outcomes of DPP-4 among diabetic patients on renal function was evaluated on the basis of estimated glomerular filtration rate (eGFR), Creatinine, microalbuminuria, macroalbuminuria data from various studies were checked among these factors microalbuminuria, and creatinine are most widely used in early clinical indicator of diabetic nephropathy $y^{39-40}$ Among DPP-4I Linagliptin is only excreted by non-renal excretion; in a 24 week study by Naoto Kamatani et al. at Toyota Kosei Hospital in Japan eGFR and creatinine was measured to study DPP-4 outcomes on renal for patients taking Linagliptin and sitagliptin ${ }^{26}$ and according to the 72 annual meeting of the diabetes Association, both concluded that there was a marginal change on renal function. But due to uniqueness of Linagliptin to be excreted through a non-renal way it is suggested to improve albuminurea. ${ }^{41,42}$

\section{Liver Function}

Liver plays an important role in regulating the bodyss blood sugar, the buildup of fat in the vital organ makes it harder to control fasting glucose levels. It also makes the body more resistant to insulin, straining the pancreas and its beta cells may aggravate the blood glucose abnormalities. A non-alcoholic fatty liver disease (NAFLD) is strongly associated with insulin resistance and hyperglycemia and it is therefore closely linked to type 2 diabetes mellitus. A gold standard technique for identifying NAFLD is liver biopsy but it is not feasible to perform an invasive and costly procedure in such a large number of population. 
In this study effect of DPP-4I on liver function was measured by Alanine aminotransferase (ALT) and alanine amino aspartate (AST) in a comparative study by Naoto Kamatani et al. comparing the effect of Sitagliptin and Linagliptin concluded that due to unique property of Linagliptin to be excreted through biliary route; it improve effect of fatty liver ${ }^{26}$ other DPP-4I such as vildagliptin and saxagliptin are partially eliminated via the liver, dose reductions are recommended in patients with minor hepatic functional impairment ${ }^{43-44}$ Measurement of liver enzymes is recommended within 3 months of beginning of treatment and use of these drug is contraindicated in patients with significant liver disease. With the possible exception of vildagliptin, none of the DPP-4I has shown hepatotoxicity in clinical trials. Vildagliptin has exhibited a low incidence of increased liver enzymes. ${ }^{45}$ However, no dosage adjustment of Linagliptin, Alogliptin, saxagliptin, or Sitagliptin is recommended in patients with liver disease. ${ }^{46}$

\section{Lipid Profile}

Fats were evaluated on the basis of the high-density lipoprotein-cholesterol (HDL-C) $(\mathrm{mg} / \mathrm{dl})$, triglycerides, total cholesterol and low-density lipoprotein-cholesterol (LDL-C) levels ( $\mathrm{mg} / \mathrm{dl})$. Naoto Kamatani et al. in a 24-week comparative study between Linagliptin and sitagliptin both drug have increased HDL to $2.9 \mathrm{mg} / \mathrm{dl}$ and $1.2 \mathrm{mg} / \mathrm{dl}$ respectively in average. ${ }^{26}$ An meta-analysis of placebo controlled trials by valentine vitale et al. on the effects on Lipid Profile of Dipeptidyl Peptidase 4 Inhibitors, Pioglitazone, Acarbose, and Sulfonylurea showed that the DPP-4I improve lipids ${ }^{47}$ by dropping total cholesterol and triglycerides whereas HDL-C has increased ${ }^{48-49}$ Monami $\mathrm{M}$ et al. conducted a systematic review on meta-analysis of DPP-4 inhibitors and lipids providing data on total cholesterol, high-density lipoprotein, and low-density lipoprotein cholesterol, and triglyceride. ${ }^{49}$ Author concluded that the difference in means for endpoint versus baseline total cholesterol in

\section{Table 1 : List of Available DPP-4 Inhibitors with Their Half-Lives}

\begin{tabular}{|c|c|c|c|c|c|}
\hline Drug name & Brand available & Dose & $\begin{array}{c}\text { FDA } \\
\text { approval }\end{array}$ & $\begin{array}{l}\text { Dosage } \\
\text { form }\end{array}$ & Half- life \\
\hline \multirow[t]{6}{*}{ Sitagliptin } & Januvia & $25 \mathrm{mg}, 50 \mathrm{mg}, 100 \mathrm{mg}$ & 2006 & tablet & $14.4 \mathrm{~h}$ \\
\hline & Istavel & $50 \mathrm{mg}, 100 \mathrm{mg}$ & & & \\
\hline & Istamet(sitagliptin+metformin) & $50 \mathrm{mg} / 500 \mathrm{mg}, 50 \mathrm{mg} / 1000 \mathrm{mg}$ & & & \\
\hline & Janumet(sitagliptin+metformin) & $50 \mathrm{mg} / 500 \mathrm{mg}, 50 \mathrm{mg}, 1000 \mathrm{mg}$ & & & \\
\hline & Zitamet(sitagliptin+metformin) & $50 \mathrm{mg} / 500 \mathrm{mg}$ & & & \\
\hline & Janumet XR CP(sitagliptin+metformin) & $100 \mathrm{mg} / 1000 \mathrm{mg}$ & & & \\
\hline \multirow[t]{4}{*}{ Linagliptin } & Trajenta & $5 \mathrm{mg}$ & 2011 & tablet & $12 \mathrm{~h}$ \\
\hline & Tradjenta & $5 \mathrm{mg}$ & & & \\
\hline & Ondero & $5 \mathrm{mg}$ & & & \\
\hline & Trajenta Duo(linagliptin+metformin) & $\begin{array}{c}2.5 \mathrm{mg} / 500 \mathrm{mg}, 2.5 \mathrm{mg} / 850 \mathrm{mg}, 2.5 \\
\mathrm{mg} / 1000 \mathrm{mg}\end{array}$ & & & \\
\hline \multirow[t]{6}{*}{ Vildagliptin } & Galvus & $50 \mathrm{mg}$ & 2008 & tablet & $2.8 \mathrm{~h}$ \\
\hline & Zomelis & $50 \mathrm{mg}$ & & & \\
\hline & Jarla & $50 \mathrm{mg}$ & & & \\
\hline & Jarla M(Vildagliptin+Metformin) & $50 \mathrm{mg} / 500 \mathrm{mg}, 50 \mathrm{mg} / 1000 \mathrm{mg}$ & & & \\
\hline & Galvus Met(Vildagliptin+Metformin) & $\begin{array}{c}50 \mathrm{mg} / 500 \mathrm{mg}, 50 \mathrm{mg} / 850 \mathrm{mg}, 50 \\
\mathrm{mg} / 1000 \mathrm{mg}\end{array}$ & & & \\
\hline & Zomelis Met (Vildagliptin+Metformin) & $50 \mathrm{mg} / 500 \mathrm{mg}$ & & & \\
\hline \multirow[t]{2}{*}{ Saxagliptin } & Onglyza & $2.5 \mathrm{mg}, 5 \mathrm{mg}$ & 2009 & tablet & $2.5 \mathrm{~h}$ \\
\hline & Kombiglyze XR(saxagliptin+metformin) & $5 \mathrm{mg} / 500 \mathrm{mg}, 5 \mathrm{mg} / 1000 \mathrm{mg}$ & & & \\
\hline \multirow[t]{4}{*}{ Alogliptin } & Nesina & $25 \mathrm{mg}$ & 2010 & tablet & $21.1 \mathrm{~h}$ \\
\hline & Vipidia & $6.25 \mathrm{mg}, 12.5 \mathrm{mg}, 25 \mathrm{mg}$ & & & \\
\hline & Kazano(Alogliptin+metformin) & $\begin{array}{c}12.5 \mathrm{mg} / 500 \mathrm{mg}, 12.5 \mathrm{mg} / 850 \\
\mathrm{mg}, 12.5 \mathrm{mg} / 100 \mathrm{mg}\end{array}$ & & & \\
\hline & Vipidomet(Alogliptin+metformin) & $12.5 \mathrm{mg} / 850 \mathrm{mg}, 12.5 \mathrm{mg} / 1000 \mathrm{mg}$ & & & \\
\hline
\end{tabular}


patients on DPP-4 inhibitors treatment was significantly higher in comparison with controls. Thus, the DPP4I offer a beneficial effect on lipid and protection of cardiovascular events.

\section{Weight}

Diabetes mellitus is a common prevalent metabolic disorder which is more often associated with obesity in DM patients. ${ }^{50}$ Patient's quality of life can be negatively affected by the underlying disease process and its complications many of the available treatment options have adverse effects such as weight gain, hypoglycemia and micro- and macrovascular complications which affect patient's willingness to continue the treatment ${ }^{51-52}$ for the management of DM a drug of choice beyond glycemia control it should help in keeping body weight steady or even achieving weight loss and limiting hypoglycemia. Monami $\mathrm{M}$ et al. in a meta-analysis study from a 41 RCTs on DPP-4I in T2DM for a duration of more than 3 months showed a better glucose control and no weight gain when used either as monotherapy or in combination with other agents. ${ }^{53}$ Vildagliptin once daily or twice daily as monotherapy or in combination for a 52 week follow-up conducted to evaluate efficacy and tolerability of vildagliptin author concluded that the blood sugar was controlled without weight gain or hypoglycemia ${ }^{54}$ in another study by Jothydev et al. comparing Sitagliptin (100 mg) with glimepiride (1-3 mg) as add on to insulin, author concluded that sitagliptin has an excellent beneficial effects ${ }^{55}$ to achieve a better glycemia control, and significantly it reduces a total daily dose of insulin required, body weight without causing hypoglycemic events.

\section{Cardiac Effects}

Cardiovascular is one of macrovascular complications among the diabetes mellitus patients which is the most cause of morbidity and mortality among DM patient. ${ }^{56-57}$ In a large study by Scirica BM et al. where a total number of 16492 patients with type 2 diabetes who had a history of or were at risk for cardiovascular events were randomly assigned into groups either to receive saxagliptin or placebo and for follow up median of 2.1 years, it concluded that there was no cardiovascular risk or benefit. ${ }^{58}$ Another randomized double blinded study of Alogliptin after acute coronary syndrome in patients with type 2 diabetes involving 5380 patients who have either an acute myocardial infarction or unstable angina for a duration of up 40 months (median of 18months) Alogliptin, didn't demonstrable cardiovascular excess in high-risk patients. ${ }^{59} \mathrm{~A}$ meta-analysis by Schweizer et al. they pooled the data from 25 phase III vildagliptin trials lasting from 12 weeks to over 2 years, where vildagliptin was used alone or combination with other anti-diabetic agents Patients received either a 50-mg dose of vildagliptin once daily (OD) ( $\mathrm{n}=1393)$, twice daily (BID) $(n=6,166)$ or active and placebo comparators $(\mathrm{n}=6,061)$, were used to evaluate Cardiovascular and Cerebrovascular safety of vildagliptin ${ }^{60}$ authors concluded that vildagliptin was not associated with an increased risk CCV events in a T2DM population, including among those who are at most risk. In a randomized controlled trial to compare cardiovascular outcome of DPP-4I and glimepiride with 6504 patients in the DPP-4 inhibitors group and 13447 patients in the glimepiride group with placebo control in this study outcome was defined as hospitalization for CVDs, including angina pectoris, myocardial infarction, transient cerebral ischemic attack, heart failure, or cerebrovascular disease or any procedure involving coronary artery bypass grafting or percutaneous coronary intervention author concluded that DPP-4I offer a cardio protective outcome. ${ }^{61}$ All of the currently available Dipeptidyl peptidase -4 inhibitors have satisfied safety criteria for the cardiovascular benefits. ${ }^{62}$

\section{Hypoglycemic Effect}

Hypoglycemia is one of most common side effect in many anti-hyperglycemia drugs. Various studies were included in other to show the effect of DPP-4I in DM patients. Williams-Herman et al. performed a metaanalysis reviewing 19 studies where one group was given sitagliptin and a comparator agent to another group. ${ }^{63}$ Sitagliptin $100 \mathrm{mg} /$ day was given either as monotherapy or in combination with other antidiabetic drugs this meta-analysis a total number of 5429 patients received sitagliptin, with 4817 in the comparator group study duration ranged from 12-206 weeks. The author concluded that there was less hypoglycemia in the Sitagliptin group than a comparable group. ${ }^{53}$ Rosenstock $\mathrm{J}$, et al. in a 52-week follow-up conducted to evaluate efficacy and tolerability of vildagliptin author concluded that vildagliptin control blood sugar without weight gain or hypoglycemia. ${ }^{54}$ Many studies were conducted to assess hypoglycemia among DPP-4 in comparison with other anti-diabetic agents have shown improves beta-cell function without weight gain or hypoglycaemia. ${ }^{63-65}$

\section{Gastrointestinal Track}

Gastro-intestinal track role start from the ingestion of food, digest food into small particles to be absorbed by the body and undigested food materials are expelled out through anus, ingestion of some drugs and contaminated substances cause GI problems. The incidence of GI due to drugs are common for many drugs. However, Sanjay Karla in his study emerging role of dipeptidyl peptidase 
-4inhibitors in management of types 2 diabetes mellitus. Author concluded that the incidence of GI by vildagliptin $50 \mathrm{mg}$ twice daily is comparable to placebo and much less to metformin $2000 \mathrm{mg}$ daily around 3 to 4 times incidence of diarrhea, nausea, abdominal pain, dyspepsia and flatulence with metformin than with vildagliptin ${ }^{66}$ the adverse events of DPP-4I are ranging from mild to moderate but with a rarely treatment discontinuation of the drugs ${ }^{67}$

\section{Pancreatitis}

Pancreatitis is the inflammation of pancreas. The inflammation of pancreas will alter the release of antagonistic hormones produced from pancreas those are insulin and glucagon into the bloodstream and therefore the food metabolism for providing energy will be changed. In this study the clinical outcomes of DPP-4I on pancreas was evaluated from various resources. Ling $\mathrm{Li}$ et al. in a systemic review and meta-analysis 60 studies $(n=353,639)$, consisting of 55 randomized controlled trials $(\mathrm{n}=33,350)$ and five observational studies (three retrospective cohort studies, and two case-control studies; $\mathrm{n}=320$,289) author concluded that the incidence of pancreatitis among patients using incretins is low and that the drugs do not increase the risk of pancreatitis. ${ }^{28}$ In a retrospective national wide cohort study conducted using the Taiwan National Health Insurance claim database involving a total number of 8526 Sitagliptin initiators and 8055 acarbose initiators who had hypertriglyceridemia or prior hospitalization history for acute pancreatitis were analyzed for the risk of hospitalization due to acute pancreatitis ${ }^{68}$ concluded that use of Sitagliptin was not associated with an increased risk of acute pancreatitis in high-risk diabetic patients with hypertriglyceridemia or with history of acute pancreatitis. Shimin Chen et al. on the meta -analysis study on the association between DPP-4I drug s and risk of acute pancreatitis involving 5 case control studies, 5 randomized controlled studies, and 3 cohort studies were selected of the 451 retrieved abstracts the randomized controlled studies and casecontrol studies have confirmed acute pancreatic whereas the cohort studies didn't confirm the association of DPP-4I with acute pancreatitis. ${ }^{69}$

\section{CONCLUSION}

DPP-4I is a good option for reducing blood sugar without causing hypoglycemia effects; it also offers additional benefits by reducing lipid profile, weight, offering renal protection and preventing cardiovascular complications among T2DM patients which is the most cause of death and hospitalization among them. However, the cost of drugs should be a challenge for low income population and life style modification can cause alteration of desired clinical outcomes.

\section{ACKNOWLEDGEMENT}

We thank PSG HOSPITALS for granting us permission to assess all required medical resources database, we would also like to show our gratitude to Dr. Andhuvan A. Gandhi Associate professor at PSG College of Pharmacy for her valuable feedback and constant encouragement, we would also like to give our sincere gratitude to all the friends and colleague for comments that greatly improved the manuscript.

\section{CONFLICT OF INTEREST}

The authors announced that there is no conflict of interest regarding this work of study.

\section{ABBREVIATIONS}

eGFR: Estimated glomerular filtration rate; RTC: Randomized controlled trial; DPP-4I: Dipeptidyl peptidase inhibitor; T2DM: Type 2 diabetes mellitus; NAFLD: Non-alcoholic fatty liver disease; ALT: Alanine amino-transferase; AST: Aspartate aminotransferase; CCV: Cardio and cerebrovascular; CVD: Cardiovascular disease; OD: Once daily; BID: Twice daily; GI: Gastrointestinal

\section{SUMMARY}

Dipeptidyl peptidase-4 inhibitors are incretin based therapy which helps in reducing blood sugar glucose in type 2 diabetes mellitus without causing hypoglycemic effect, they also provide great advantages in preventing cardiovascular complications due to their ability to control lipid profile and body weight.

\section{REFERENCES}

1. Callaghan BC, Little AA, Feldman EL, Hughes RAC. Enhanced glucose control for preventing and treating diabetic neuropathy. Cochrane Database of Systematic Reviews. 2012;(6). Art. No.: CD007543.

2. Amod A, Ascott-Evans BH, Berg Gl, et al. The 2012 SEMDSA guideline for the management of type 2 diabetes (revised). JEMDSA. 2012;17(2 Suppl 1):S1-S95.

3. Diabetes. Mayo Clinic [homepage on the Internet]. 2015. c2015. Available from: http://www.mayoclinic.org/diseases conditions/ diabetes/ basics/ complications/ con20033091

4. National Institute of Diabetes. Prevent diabetes problems: keep your diabetes under control. NID [homepage on the Internet].2015. c2015. Available from: http://www. niddk.nih.gov/health-information/health-topics/Diabetes/preventdiabetes-problems/Pages/index.aspx 
5. Standards of medical care in diabetes-2016: Summary of revisions. Diabetes Care. 2016;39(Suppl 1):S4-5. [PubMed]

6. Haffner SM, Lehto S, Ronnemaa T, et al. Mortality from coronary heart disease in subjects with type 2 diabetes and in nondiabetic subjects with and without prior myocardial infarction. N Engl J Med. 1998;339(4):229-34.

7. Scheidt-Nave C, Barrett-Connor E, Wingard DL. Resting electrocardiographic abnormalities suggestive of asymptomatic ischemic heart disease associated with noninsulin-dependent diabetes mellitus in a defined population. Circulation. 1990;81(3):899-906.

8. Grundy SM, Benjamin IJ, Burke GL, et al. Diabetes and cardiovascular disease: a statement for healthcare professionals from the American Heart Association. Circulation. 1999;100(10):1134-46.

9. Howard BV, Magee MF. Diabetes and cardiovascular disease. Curr Atheroscler Rep. 2000;2:476-81.

10. Holst JJ. Gromada J2004 Role of incretin hormones in the regulation of insulin secretion in diabetic and nondiabetic humans. Am J Physiol Endocrinol Metab. 2004;287(2):E199-E206.

11. Guariguata L, Whiting D, Weil C, Unwin N. The International Diabetes Federation diabetes atlas methodology for estimating global and national prevalence of diabetes in adults. Diabetes Res Clin Pract. 2011;94(3):322-2. http://dx.doi. org/10.1016/j.diabres.2011.10.040.

12. IDF Diabetes Complications and Foot Congress 2018.

13. Aguiree F, Brown A, Cho NH, Dahlquist G, Dodd S, Dunning T, et al. IDF Diabetes Atlas. 2013.

14. Anjana RM, Pradeepa R, Deepa M, Datta M, Sudha V, Unnikrishnan R, et al. Prevalence of diabetes and prediabetes (impaired fasting glucose and/ or impaired glucose tolerance) in urban and rural India: phase I results of the Indian Council of Medical Research-India Diabetes (ICMR-INDIAB) study. Diabetologia. 2011;54(12):3022-7.

15. Little M, Humphries S, Patel K, Dodd W, Dewey C. Factors associated with glucose tolerance, pre-diabetes, and type 2 diabetes in a rural community of south India: a cross-sectional study. Diabetol Metab Syndr. 2016;8(1):21.

16. Ramachandran A, Snehalatha C, Kapur A, Vijay V, Mohan V, Das AK, et al. High prevalence of diabetes and impaired glucose tolerance in India: National Urban Diabetes Survey. Diabetologia. 2001;44(9):1094-101.

17. Barik A, Mazumdar S, Chowdhury A, Rai RK. Physiological and behavioral risk factors of type 2 diabetes mellitus in rural India. BMJ Open Diabetes Res Care. 2016;4(1):e000255

18. Ajay VS, Prabhakaran D, Jeemon P, Thankappan KR, Mohan V, Ramakrishnan L, et al. Prevalence and determinants of diabetes mellitus in the Indian industrial population. Diabet Med. 2008;25(10):1187-94

19. The Diabetes Control and Complications Trial Research Group. The effect of intensive treatment of diabetes and development and progression of long term complications. N Engl J Med. 1993;329:977-86.

20. United Kingdom Prospective Study Group. Intensive blood-glucose contro with sulphonyl urea or insulin compared with conventional treatment and risk of complications in patients with type 2 diabetes (UKPDS 33). Lancet. 1998;352:837-53.

21. Reusch JE, Manson JE. Management of Type 2 Diabetes in 2017 Getting to Goal. JAMA. 2017;317(10):1015-6

22. Helmrich SP, Ragland DR, Leung RW, Paffenberger RS. Physical activity and reduced occurrence of NIDDM. N Engl J Med. 1991;324:147-52.

23. Deacon CF. Dipeptidyl peptidase- 4 inhibitors in the treatment of type 2 diabetes: A comparative review. Diabetes Obes Metab. 2011;13(1):7-18.

24. Deacon CF, Knudsen LB, Madsen K, Wiberg FC, Jacobsen O, Holst JJ. Dipeptidyl peptidase IV resistant analogues of glucagon-like peptide-1 which have extended metabolic stability and improved biological activity. Diabetologia 1998;41(3):271-8.

25. Stephen Kay, Amanda S, Jorge P, et al. Comparative Effectiveness of Adding Alogliptin to Metformin Plus Sulfonylurea with Other DPP-4Inhibitors in Type 2 Diabetes: A Systematic Review and Network Meta-Analysis. Diabetes Ther. 2017;8(2):251-73.

26. Naoto K, Taiya K, et al. Comparison between the clinical efficacy of linagliptin and sitagliptin. J Diabetes Endocrinol. 2013;4(4):51-4.

27. Green JB, Bethel MA, Armstrong PW, et al. Effect of sitagliptin on cardiovascular outcomes in type 2 diabetes. N Engl J Med. 2015;373(3):232-42.

28. Ling Li, Jiantong $\mathrm{S}$, et al. Incretin treatment and risk of pancreatitis in patients with type 2 diabetes mellitus: systematic review and meta-analysis of randomised and non-randomised studies. BMJ. 2014;348:g2366.
29. Ahren B, Simonsson E, Larsson H, Landin-Olsson M, Torgeirsson H, JanssonPA et al. Inhibition of dipeptidyl peptidase IV improves metabolic control over a 4-week study period in type 2 diabetes. Diabetes Care. 2002;25:869-75.

30. Gary AH, Arthur B, et al. Effect of Single Oral Doses of Sitagliptin, a DipeptidylPeptidase-4 Inhibitor, on Incretin and Plasma Glucose Levels after an Oral Glucose Tolerance Test in Patients with Type 2 Diabetes. J Clin Endocrinol Metab. 2006;91(11):4612-9.

31. Johnson KI, Craddy $\mathrm{P}$, Palin HJ. Comparative effectiveness dipeptidylpeptidase-4 inhibitors in type 2 diabetes: a systematic review and mixed treatment comparison. Diabetes Ther. 2014;5(1):1-41.

32. Schuetz $\mathrm{CA}$, Ong SH, Blüher M. Clinical trial simulation methods for estimating the impact of DPP-4 inhibitors on cardiovascular disease. Clinico Econ Outcomes Res. 2015;7:313. pMC4462855.

33. NauckM SU. Incretin-based therapy: how do incretin mimetics and DPP4inhibitors fit into treatment algorithms for type 2 diabetic patients?. Best Pract Res Clin Endocrinol Metab. 2009;23(4):513-23.

34. Craddy P, Palin HJ, Johnson KI. Comparative effectiveness of dipeptidylpeptidase-4 inhibitors in type 2 diabetes: a systematic review and mixed treatment comparison. Diabetes Ther. 2014;5(1):1-41.

35. Nasser M. Combination therapy with DPP-4 inhibitors and pioglitazone in type 2 diabetes: theoretical consideration and therapeutic potential. Vasc Health Risk Manag. 2008;4(6):1221-7

36. Richter B, Bandeira-Echtler E, Bergerhoff K, et al. Dipeptidyl peptidase4(DPP-4) inhibitors for type 2 diabetes mellitus. Cochrane Database Syst Rev. 2008:CD390067

37. Amori RE, Lau J, Pittas AG. Efficacy and safety of incretin therapy in type 2diabetes: systematic review and meta-analysis. JAMA. 2007;298(2):194-206

38. Lee SY, Choi ME. Urinary biomarkers for early diabetic nephropathy: beyond albuminuria. Pediatr Nephrol. 2015;30(7):1063-75.

39. Rigalleau V, Beauvieux MC, Gonzalez C, et al. Estimation of renal function in patients with diabetes. Diabetes Metab. 2011;37(5):359-66

40. Dejager $S$, et al. Incretin therapies in the management of patients with type 2 diabetes mellitus and renal impairment. Hosp Pract. 2012;40(2):7-21.

41. Heise T, Graefe-Mody EU, Hüttner S, Ring A, Trommeshauser D, Dugi KA. Pharmacokinetics, pharmacodynamics and tolerability of multiple oral doses of linagliptin, a dipeptidyl peptidase-4 inhibitor in male type 2 diabetes patients. Diabetes Obes. Metab. 2009;11(8):786-94.

42. Groop P, Cooper M, Perkovic V, Emser A, Von EM, Woerle H. Linagliptin Lowers Albuminuria on Top of Recommended Standard Treatment for Diabetic Nephropathy. Poster No. 953-P. Presented at the American Diabetes Association $\circledast$ ADA $72^{\text {nd }}$ Scientific Sessions. 2012;8-12. Philadelphia, PA

43. Deacon CF. Dipeptidyl peptidase- 4 inhibitors in the treatment of type 2 diabetes: a comparative review. Diabetes Obes Metab. 2011;13(1):7-18.

44. Deacon CF, Knudsen LB, Madsen K, Wiberg FC, Jacobsen O, Holst JJ. Dipeptidyl peptidase IV resistant analogues of glucagon-like peptide-1 which have extended metabolic stability and improved biological activity. Diabetologia. 1998;41(3):271-8.

45. Emea.europa.edu [homepage on the internet]. Summary of product characteristics of vildagliptin2007. Available from: http://www.ema.europa.eu/ docs/en_GB/document_library/EPAR_Product_Information/human/000771/ WC500020327.pdf.

46. Sri HT, Marc SR. DPP-4 inhibitors: focus on safety. Expert Opin. Drug Saf. 2015;14(1):127-40

47. Matteo M, Valentina V, Maria LA, et al. Effects on Lipid Profile of Dipeptidyl Peptidase 4 Inhibitors, Pioglitazone, Acarbose, and Sulfonylureas: Metaanalysis of Placebo-Controlled Trials. Adv Ther. 2012;29(9):736-46.

48. Wataru Y, Noriyuki I, et al. Mechanism of lipid-lowering action of the dipeptidyl peptidase-4 inhibitor, anagliptin, in low-density lipoprotein receptor-deficient mice. J Diabetes Investig. 2017;8(2):155-60

49. Monami M, Lamanna C, Desideri CM, Mannucci E. DPP-4 inhibitors and lipids: systematic review and meta-analysis. Adv Ther. 2012;29(1):14-25.

50. Kaustubh N, Ram K, et al. Comparison of efficacy between incretin-based therapies for type 2 diabetes mellitus. BMC Medicine. 2012;10(1):152.

51. Jacobson AM. Impact of improved glycemic control on quality of life in patients with diabetes. Endocr Pract. 2004;10(6):502-8.

52. Kanazawa I, Tanaka KI, Notsu M, et al. Long-term efficacy and safety of vildagliptin add-on therapy in type 2 diabetes mellitus with insulin treatment. Diabetes Res Clin Pract. 2017;123:9-17.

Indian Journal of Pharmacy Practice, Vol 11, Issue 3, Jul-Sep, 2018 
53. Monami M, lacomelli I, Marchionni N, Mannucci E. Dipeptidyl peptidase-4 inhibitors in type 2 diabetes: a meta-analysis of randomized clinical trials. Nutr Metab Cardiovasc Dis. 2010;20(4):224-35

54. Rosenstock J, Pi-Sunyer FX, Pratley RE, et al. Robust efficacy of vildagliptin in drug-naive patients: pooled analysis of 5 monotherapy studies [abstract no. 506-P]. $67^{\text {th }}$ Annual Scientific Sessions of the American Diabetes Association. 2007; Chicago (IL), A135.

55. Jothydev K, Pradeep B, Sadasivan P, Arun S, et al. Sitagliptin $100 \mathrm{mg}$ vs glimepiride $1-3 \mathrm{mg}$ as an add-on to insulin and metformin in type 2 diabetes (SWIM). Endocr Connect. 2017;6(8):748-57.

56. Martín-Timón I, Sevillano-Collantes C, et al. Type 2 diabetes and cardiovascular disease. Have all risk factors the same strength: World J Diabetes. 2014;5(4):444-70.

57. Gu K, Cowie CC, Harris MI. Diabetes and decline in heart disease mortality in US adults. JAMA. 1999;281(14):1291-7.

58. Scirica BM, Bhatt DL, Braunwald E, et al. SAVOR-TIMI 53 Steering Committee and Investigators. Saxagliptin and cardiovascular outcomes in patients with type 2 diabetes mellitus. N Engl J Med. 2013;369:1317-26.

59. White WB, Cannon CP, Heller SR, et al. EXAMINE Investigators Alogliptin after acute coronary syndrome in patients with type 2 diabetes. $\mathrm{N}$ Engl $\mathrm{J}$ Med. 2013;369(14):1327-35.

60. Schweizer A, Dejager S, Foley JE. Assessing the cardio cerebrovascular safety of vildagliptin: meta-analysis of adjudicated events from a large Phase III type 2 diabetes population. Diabetes Obes Metab. 2010;12(6):485-94.
61. Hyouk-Jun C, Jin HN, et al. Comparative safety for cardiovascular outcomes of DPP-4 inhibitors versus glimepiride in patients with type 2 diabetes A retrospective cohort study. Medicine (Baltimore). 2017;96(25):e7213.

62. David MC, Russell D, Miles F. Cardiovascular safety and DPP-4 inhibitors. Practical Diabetes. 2013;30(2):78-81.

63. Pratley RE, Jauffret-Kamel S, Galbreath E, Holmes D. Twelve-week monotherapy with the DPP-4 inhibitor vildagliptin improves glycemic control in subjects with type 2 diabetes. Horm Metab Res. 2006;38:423-8.

64. Scherbaum WA, Schweizer A, Mari A, Nilsson PM, Lalanne G, Jauffret S, et al. Efficacy and tolerability of vildagliptin in drug naïve patients with type 2 diabetes and mild hyperglycemia. Diabetes Obes Metab. 2008;10(8):675-82.

65. Schweizer A, Couturier A, Foley JE, Dejager S. Comparison between vildagliptin and metformin to sustain reductions in $\mathrm{HbA}(1 \mathrm{c})$ over 1 year in drugnaïve patients with Type 2 diabetes. Diabet Med. 2007;24(9):955-61.

66. Sanjay K. Emerging role of dipeptidyl peptidase-4 inhibitor vildagliptin in the management of types 2 diabetes mellitus. J Assoc Physicians India. 2011;59:237.

67. Revathi P, Bhuvaneswari S, Sarojini K, Jeyaseelan S, et al. Role of vildagliptindipeptidyl peptidase-4 inhibitor in patients with type 2 diabetes mellitus-an overview. EJBPS. 2015;2(3):1067-83.

68. Xiwen C, et al. Dipeptidyl Peptidase-4 Inhibitor Use Is Not Associated with Acute Pancreatitis in High-Risk Type 2 Diabetic Patients. Medicine. 2016;95(7):e2603A

69. Shimin C, Wenfei L, Jiehong W. Association between dipeptidyl peptidase4 inhibitor drugs and risk of acute pancreatitis A meta-analysis. Medicine. 2017;96:48(e8952) 